\title{
Glycerophospholipids protect stallion spermatozoa from oxidative damage in vitro
}

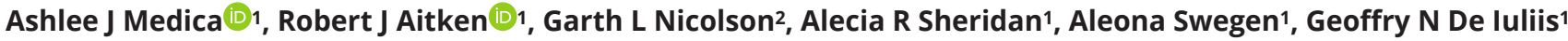 \\ and Zamira Gibb1
}

1Priority Research Centre for Reproductive Science, College of Engineering, Science and Environmental, and Faculty of Health and Medicine, University of Newcastle, Callaghan, New South Wales, Australia

2Institute for Molecular Medicine, Huntington Beach, California, USA

Correspondence should be addressed to A J Medica: ashlee.medica@uon.edu.au

\begin{abstract}
Stallion sperm membranes comprise a high proportion of polyunsaturated fatty acids, making stallion spermatozoa especially vulnerable to peroxidative damage from reactive oxygen species generated as a by-product of cell metabolism. Membrane lipid replacement therapy with glycerophospholipid (GPL) mixtures has been shown to reduce oxidative damage in vitro and in vivo. The aims of this study were to test the effects of a commercial preparation of GPL, NTFactor ${ }^{\circledR}$ Lipids, on stallion spermatozoa under oxidative stress. When oxidative damage was induced by the addition of arachidonic acid to stallion spermatozoa, the subsequent addition of GPL reduced the percentage of 4-hydroxynonenal (4-HNE; a key end product of lipid peroxidation) positive cells ( $32.9 \pm 2.7$ vs $20.9 \pm 2.3 \% ; P \leq 0.05)$ and increased the concentration of 4-HNE within the spent media $(0.026 \pm 0.003$ vs $0.039 \pm 0.004 \mu \mathrm{g} / \mathrm{mL} ; P \leq 0.001)$, suggesting that oxidized lipids had been replaced by exogenous GPL. Lipid replacement improved several motility parameters (total motility: $2.0 \pm 1.0$ vs $68.8 \pm 2.9 \%$; progressive motility: $0 \pm 0$ vs $19.3 \pm 2.6 \%$; straight line velocity: $9.5 \pm 2.1$ vs $50.9 \pm 4.1 \mu \mathrm{m} / \mathrm{s}$; curvilinear velocity: $40.8 \pm 10 \mathrm{vs} 160.7 \pm 7.8 \mu \mathrm{m} / \mathrm{s}$; average path velocity: $13.4 \pm 2.9$ vs $81.9 \pm 5.9 \mu \mathrm{m} / \mathrm{s} ; P \leq 0.001)$, sperm viability $(13.5 \pm 2.9 \mathrm{vs} 80.2 \pm 1.6 \% ; P \leq 0.001)$ and reduced mitochondrial ROS generation ( $98.2 \pm 0.6$ vs $74.8 \pm 6.1 \% ; P \leq 0.001)$. Supplementation with $\mathrm{GPL}$ during $17^{\circ} \mathrm{C}$ in vitro sperm storage over $72 \mathrm{~h}$ improved sperm viability $(66.4 \pm 2.6 \mathrm{vs} 78.1 \pm 2.9 \% ; P \leq 0.01)$ and total motility (53 \pm 5.6 vs $66.3 \pm 3.5 \% ; P \leq 0.05$ ). It is concluded that incubation of stallion spermatozoa with sub- $\mu \mathrm{m}$-sized GPL micelles results in the incorporation of exogenous GPL into sperm membranes, diminishing lipid peroxidation and improving sperm quality in vitro.
\end{abstract}

\section{Lay summary}

Sperm collection and storage is an important step in many artificial insemination and in vitro fertilization regimes for several species, including humans and horses. The sperm membrane, which acts as a protective outer barrier, is made up of fatty acid-containing molecules - called phospholipids. These phospholipids may become damaged by waste products generated by the cell, such as hydrogen peroxide, during non-chilled sperm storage. We aimed to determine if sperm cells were able to repair this membrane damage by supplementing them with phospholipids during non-chilled storage. Sperm was collected from five miniature stallions by artificial vagina, and then supplemented with phospholipids during $72 \mathrm{~h}$ sperm storage at $17^{\circ} \mathrm{C}$. Our studies show that when stallion sperm are supplemented with phospholipids in vitro, they are able to remove their damaged membrane phospholipids and swap them for undamaged ones, aiding in resistance to cellular waste and improving cell health and potential fertility.

Key Words: - stallion spermatozoa $\quad$ sperm membrane $\quad$ membrane lipid replacement $\quad$ reactive oxygen species 


\section{Introduction}

The sperm plasma membrane is far more than just an inert barrier. It actively protects spermatozoa against extracellular damage and plays a dynamic role throughout sperm capacitation and in sperm-oocyte cross talk during fertilisation (Flesch \& Gadella 2000, Ortega Ferrusola et al. 2010). The plasma membrane and additional inner organelle membranes are comprised of several types of phospholipids, each exhibiting a specific and unique structure and distinctive fatty acid profile (Lenzi et al. 1996, Fahy et al. 2005). These phospholipid classes include those with saturated, mono-unsaturated and polyunsaturated fatty acids (PUFA); sperm membranes are comprised of an extremely high percentage of the latter (22:6; polyunsaturated-to-saturated; Aitken et al. 1989). This high proportion of PUFA makes spermatozoa especially vulnerable to peroxidative damage from reactive oxygen species (ROS) such as superoxide, and hydrogen peroxide $\left(\mathrm{H}_{2} \mathrm{O}_{2}\right.$; Saleh \& Agarwal 2002, Saalu 2010). Mitochondrial membranes are particularly susceptible to ROS attack due to mitochondria being one of the primary producers of ROS (Zorov et al. 2014), the main instigator of membrane lipid peroxidation (Aitken 1995). A derivative of lipid peroxidation is 4-hydroxynonenal (4-HNE); it is one of the most researched products of lipid metabolism due to its reactivity and cytotoxicity (Spickett 2013). Once produced, 4-HNE can form adducts, modifying the functions of multiple targets within the sperm proteome such as $\alpha$-tubulin (Baker et al. 2015), heat shock proteins (HSP; Bromfield et al. 2017) and succinate dehydrogenase (SDHA; Aitken et al. 2012b). Modification of SDHA by 4-HNE adduction dramatically increases mitochondrial superoxide production and causes a loss of the mitochondrial membrane potential (MMP; Aitken et al. 2012b). The loss of MMP also results in a decrease in the generation of ATP from mitochondrial respiration, leading eventually to cell death (Gaschler \& Stockwell 2017, Uribe et al. 2017).

Dietary Membrane Lipid Replacement (MLR) supplements (NTFactor ${ }^{\circ}$ Lipids) are a novel therapeutic tool that allows damaged glycerophospholipids (GPL) in biological membranes to be replaced with exogenously supplied, undamaged GPL (Nicolson 2005, 2010, 2014, 2016, Nicolson \& Ellithorpe 2006, Nicolson \& Ash 2014). These supplements contain a mixture of the most common glycerophospholipids found within cell membranes, as well as unsaturated fatty acids (Nicolson \& Ash 2017). Somatic cell studies have shown that MLR therapy allows peroxidised lipids in both the plasma and mitochondrial membranes to be replaced with exogenous GPL when somatic cells are exposed to an oxidative stress challenge (Nicolson \& Ellithorpe 2006, Nicolson 2007, Nicolson \& Conklin 2008). Interestingly, this phenomenon has also been demonstrated using human spermatozoa; GPL supplementation in vitro improved MMP, restored cellular functions and increased resistance to oxidative stress (Ferreira et al. 2018). Despite these promising in vitro results, there is an absence of experimental evidence showing the effects of MLR therapy in conjunction with artificial reproduction technologies such as sperm storage. Sperm storage technologies are a vital aspect of all equine artificial insemination programmes, and these storage methods can exert stressors that are quite detrimental to spermatozoa (Brinsko et al. 2000a,b, Batellier et al. 2001, Aurich 2005). It was hypothesised that the addition of sub$\mu \mathrm{m}$-sized glycerophospholipids to stallion spermatozoa during an in vitro oxidative challenge and during in vitro storage would provide protection against oxidative damage. As such, the overarching aim of this investigation was to investigate whether stallion spermatozoa are able to undergo membrane lipid replacement in the presence of physiological oxidative stressors, and if so, to ascertain whether the post-storage quality of stallion spermatozoa could be improved by in vitro GPL supplementation.

\section{Materials and methods}

\section{Materials}

Unless otherwise stated, all chemicals were purchased from Sigma-Aldrich (Australia). A modified Biggers, Whitten and Whittingham medium (BWW) a synthetic oviductal fluid (Biggers et al. 1971); containing $95 \mathrm{mM} \mathrm{NaCl}, 4.7 \mathrm{mM}$

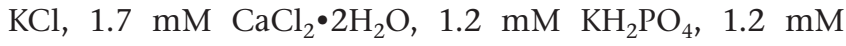
$\mathrm{MgSO}_{4} \bullet 7 \mathrm{H}_{2} \mathrm{O}, 25 \mathrm{mM} \mathrm{NaHCO}{ }_{3}, 5.6 \mathrm{mM}$ D-glucose, $275 \mu \mathrm{M} \mathrm{C}_{3} \mathrm{H}_{3} \mathrm{NaO}_{3}, 3.7 \mu \mathrm{L} / \mathrm{mL} 60 \% \mathrm{NaC}_{3} \mathrm{H}_{5} \mathrm{O}_{3}$ syrup, $50 \mathrm{U} / \mathrm{mL}$ penicillin, $50 \mu \mathrm{g} / \mathrm{mL}$ streptomycin, $20 \mathrm{mM}$ HEPES and $0.1 \%(\mathrm{w} / \mathrm{v})$ polyvinyl alcohol, with an osmolarity of approximately $310 \mathrm{mOsm} / \mathrm{kg}$ and a $\mathrm{pH}$ of 7.4 was utilized throughout this study.

\section{Semen collection and preparation}

Institutional and New South Wales State Government ethical approval was secured for the use of animal material in this study. All experiments were based on multiple ejaculates from five normozoospermic Shetland and miniature crossbred pony stallions (between 3 and 15 years of age) of proven fertility, held on institutionally approved

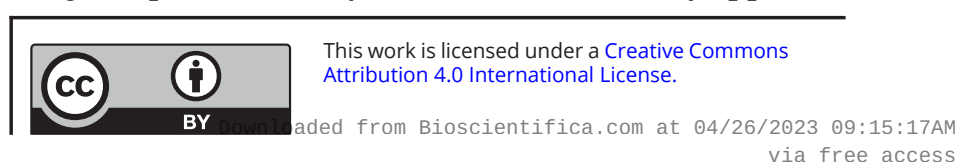


premises. The stallions had access to native pasture $24 \mathrm{~h}$ a day and were supplementary fed with grass and lucerne hay once daily. Semen was collected using a pony-sized Missouri artificial vagina (AV; Minitube, Ballarat, VIC, Australia) with an in-line semen filter. The ejaculate was immediately diluted (2:1; extender:semen) with EquiPlus semen extender (Minitube, Ballarat, VIC, Australia).

Equipment and extender were maintained at temperatures between 30 and $37^{\circ} \mathrm{C}$ for the duration of semen collection and dilution. The tubes of extended semen were then transported to the laboratory in a polystyrene box at room temperature (RT; approximately $20-25^{\circ} \mathrm{C}$ ). Once stallion semen samples were delivered to the laboratory, a maximum of $6 \mathrm{~mL}$ of extended semen was overlayed onto $3 \mathrm{~mL}$ of EquiPure (colloid gradient; Tek-Event Pty Ltd, Australia) and centrifuged at $400 \boldsymbol{g}$ for $20 \mathrm{~min}$. After removing the supernatant, the pelleted cells were resuspended in $1 \mathrm{~mL}$ of BWW solution for determination of sperm concentration.

Sperm concentrations were determined using a NucleoCounter NC-100 ${ }^{\text {m }}$ (ChemoMetec, Denmark). Samples were then diluted out to approximately 20 to $25 \times 10^{6} \mathrm{sperm} / \mathrm{mL}$ in BWW solution (unless otherwise stated). Washed spermatozoa were stored under aerobic conditions for all subsequent procedures.

\section{Preparation of sub-micrometre-sized glycerophospholipid micelles}

Nutritional Therapeutics, Inc. (Hauppuage, NY, USA) specifically prepared the formulation of NTFactor ${ }^{\circ}$ Lipids for use in this study, which omitted the fructooligosaccharides from the formulation that are contained within the traditional dietary supplement to protect the GPL against degradation within the digestive system. GPL micelle stock solutions were prepared by adding $3 \%(\mathrm{w} / \mathrm{v})$ modified NTFactor Lipids (Nutritional Therapeutics, Inc. of Hauppuage, NY, USA) to BWW. For micelle formation; ethanol ( $0.1 \%$ final volume) was added to the mixture, which was then vortexed until visibly dissolved. The GPL mixture was then placed in an ice bath and ultrasonicated at $20 \mathrm{kHz}$ intermittently for $20 \mathrm{~min}$ (5 s on, $5 \mathrm{~s}$ off) using a probe sonicator (Bandelin Sonoplus, Germany). The resulting product was filtered through a $0.2 \mu \mathrm{m}$ sterile syringe filter to isolate sub-micrometre-sized micelles as previously described (Ferreira et al. 2018).

\section{Evaluation of sperm motility}

Computer assisted sperm analysis (CASA; IVOS, Hamilton Thorne, Danvers, MA) was used to objectively assess the motility parameters of sperm cells. The following settings were used; negative phase-contrast optics, recording rate of 60 frames/s, minimum cell size of $5 \mu \mathrm{m}^{2}$, maximum cell size of $50 \mu \mathrm{m}^{2}$, progressive average path velocity (VAP) threshold of $50 \mu \mathrm{m} / \mathrm{s}$, slow (static) cell VAP threshold of $20 \mu \mathrm{m} / \mathrm{s}$, slow (static) cell velocity (VSL) threshold of $0 \mu \mathrm{m} / \mathrm{s}$, and threshold straightness (STR) of $75 \%$. Cells exhibiting a VAP of $\geq 50 \mu \mathrm{m} / \mathrm{s}$ and an STR of $\geq 80 \%$ were considered progressive. A total of $3 \mu \mathrm{L}$ of sperm from each sample was loaded into one chamber of a $20 \mu \mathrm{m}$ deep fourchambered slide (Leja; Gytech Pty Ltd, Australia) with a stage temperature of $37^{\circ} \mathrm{C}$. At minimum, 200 cells and 5 fields were analysed per sample.

\section{Flow cytometric analysis}

All flow cytometry was performed using a FACSCanto II flow cytometer (Becton Dickinson, CA) with a 488-nm solid state laser. Emission measurements were made using $530 / 30 \mathrm{~nm}$ band pass (green/FITC), 585/42 $\mathrm{nm}$ band pass (red/PE), $>670 \mathrm{~nm}$ long pass (far red/PerCp) and 780/60 nm band pass (far red/PECy7) filters. Using the forward scatter/ side scatter dot plot, a gate was drawn and placed around the sperm population, excluding debris from the analysis. A minimum of 10,000 cells were analysed from each sample using FACSDiva V8.01 software (Becton Dickinson, CA).

\section{Flow cytometric measurement of mitochondrial ROS}

The MitoSOX ${ }^{\text {m }}$ Red (MSR) reagent is membrane permeable and by virtue of its charge can specifically target the mitochondria. Under conditions of high mitochondrial ROS, the reagent is oxidized by superoxide and becomes highly fluorescent, allowing for a direct measurement of mitochondrial superoxide production. To run the MSR assay, $100 \mu \mathrm{L}$ of sperm suspension was incubated for 15 min at $37^{\circ} \mathrm{C}$ with $2 \mu \mathrm{M}$ MSR stain (Molecular Probes) and $5 \mathrm{nM}$ SYTOX $^{\mathrm{mm}}$ Green (Molecular Probes) viability stain. Staining controls included a positive dead control: $100 \mu \mathrm{L}$ of spermatozoa was snap-frozen in liquid nitrogen and incubated for $15 \mathrm{~min}$ at $37^{\circ} \mathrm{C}$ with $5 \mathrm{nM}$ SYTOX ${ }^{\mathrm{m}}$ Green viability stain only; and an MSR positive control: $100 \mu \mathrm{L}$ of sperm was incubated for $15 \mathrm{~min}$ with $100 \mu \mathrm{M}$ arachidonic acid (AA) and $2 \mu \mathrm{M}$ MSR stain only. The spermatozoa were then centrifuged at $500 \boldsymbol{g}$ for $3 \mathrm{~min}$; the supernatant was removed, and pellets were resuspended in $300 \mu \mathrm{L}$ BWW for analysis by FACSCanto II. As all dead cells are read positive for MSR (due to an artefact associated with the ethidiumbased fluorophore), only live-cell data were collected for statistical analyses.

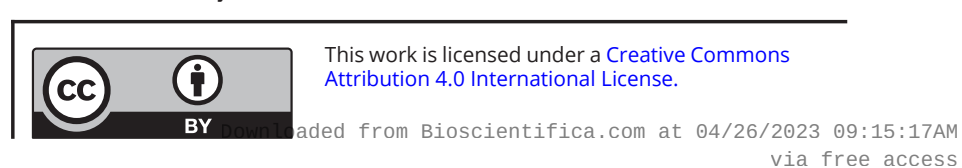


Flow cytometric measurement of cellular 4-hydroxynonenal adduction

4-Hydroxynonenal (4-HNE) is a well-characterized derivative of lipid peroxidation and is a stable marker for measuring levels of oxidative stress. To measure 4-HNE levels in spermatozoa, $100 \mu \mathrm{L}$ of sperm were centrifuged at $500 \boldsymbol{g}$ for $3 \mathrm{~min}$, the supernatant was snap-frozen in liquid nitrogen for use in subsequent experiments, and sperm pellets were resuspended in $50 \mu \mathrm{L}$ of BWW containing 0.02 $\mu \mathrm{g} / \mu \mathrm{L}$ (1:50 of antibody as supplied) rabbit $\alpha$-HNE primary antibody (Abcam) and 1:2000 (v/v) LIVE/DEAD ${ }^{\text {Tm }}$ Fixable Far Red Dead Cell stain (Molecular Probes). Samples were incubated at $37^{\circ} \mathrm{C}$ for $30 \mathrm{~min}$. Spermatozoa were then centrifuged at $500 \mathrm{~g}$ for $3 \mathrm{~min}$; the supernatant was removed, and pellets resuspended in $100 \mu \mathrm{L}$ BWW containing $2 \mu \mathrm{g} / \mu \mathrm{L}$ goat $\alpha$-rabbit IgG peroxidase conjugate (Alexa Fluor 488 goat $\alpha$-rabbit secondary antibody) and incubated at $37^{\circ} \mathrm{C}$ for $15 \mathrm{~min}$. Spermatozoa were centrifuged at $500 \boldsymbol{g}$ for $3 \mathrm{~min}$, supernatant was removed, and pellets were washed a second time to remove all unbound antibody. Spermatozoa were then resuspended in $300 \mu \mathrm{L}$ BWW and placed into clean FACS tubes for analysis by FACSCanto II. To allow for specific gating, staining controls were used. These included; snap-frozen LIVE/DEAD ${ }^{\text {Tm }}$ positive control, where $100 \mu \mathrm{L}$ of spermatozoa was snap-frozen in liquid nitrogen, thawed, and incubated for $30 \mathrm{~min}$ at $37^{\circ} \mathrm{C}$ with 1:2000 (v/v) LIVE/DEAD ${ }^{\mathrm{Tm}}$ Fixable Far Red Dead Cell stain only, and a secondary antibody (Alexa Fluor 488 goat $\alpha$-rabbit secondary antibody) only control.

Additionally, spermatozoa were incubated with $50 \mu \mathrm{M}$ AA with and without the addition of GPL for $2 \mathrm{~h}$ at $37^{\circ} \mathrm{C}$. The staining protocols for flow cytometric measurement of cellular 4-HNE adduction were followed, as described above, with some modifications; the LIVE/DEAD ${ }^{\mathrm{Tm}}$ stain was substituted with $7.5 \mu \mathrm{M}$ propidium iodide (PI; added immediately before assessment). Spermatozoa were mounted on slides with paraformaldehyde $(0.01 \%, \mathrm{v} / \mathrm{v})$ to suppress motility. Representative images of spermatozoa were taken with fluorescent microscopy.

\section{Measurement of 4-hydroxynonenal within the spent media}

Concentration of 4-HNE adducts within the snap-frozen supernatant (spent media) collected as outlined in 'Flow cytometric measurement of cellular 4-hydroxynonenal adduction' section, was analysed with the Lipid Peroxidation (4-HNE) ELISA Kit (Abcam) as per the manufacturer's instructions.

\section{Statistical analyses}

All statistical analyses were conducted using JMP Pro, version 14.2.0 (SAS Institute, Cary, NC). A Student's $t$-test and was used when comparing two treatments to determine if the observed changes that occurred with treatments were greater than what could be probable by chance. For $17^{\circ} \mathrm{C}$ storage experiments, a REML analysis was used to compare repeated measures over time. For this model, stallion name was selected as a random effect, and comparisons were made within time points; comparison of group mean values with the corresponding controls was achieved using Dunnett's test. These parametric methods were only used if the data distribution was normal according to the Anderson-Darling goodness-of-fit test, while the assumed homogeneity of variances was checked using the Bartlett test. Where the data were not normally distributed, the non-parametric Wilcoxon signed-rank test was used. The specific tests used for each section of this study are clearly indicated within the figure legends. Significance was determined when $P \leq 0.05$. All data are displayed as means \pm S.E.M.

\section{Experimental design}

Experiment 1: Incubation of stallion spermatozoa with glycerophospholipids in the presence of induced oxidative stress

Stallion spermatozoa were exposed to increasing concentrations of $\mathrm{AA}(0,25,50$ and $100 \mu \mathrm{M}$; concentrations which have been used in previous studies, and reflects physiological AA concentrations within cells; Moazamian et al. 2015, Tallima \& El Ridi 2018) to induce oxidative stress, with and without the addition of GPL at a final concentration of $0.1 \%(\mathrm{v} / \mathrm{v}$; a concentration which has previously been optimized for use with human spermatozoa; Ferreira et al. 2018). Samples were incubated at $37^{\circ} \mathrm{C}$ for $1 \mathrm{~h}$ ( $n=9$ ejaculates), then analysed for motility ('Evaluation of sperm motility' section), viability (SYTOX ${ }^{\mathrm{T}}$ green; 'Flow-cytometric measurement of mitochondrial ROS' section) and mitochondrial ROS (MSR; 'Flow cytometric measurement of mitochondrial ROS' section). To avoid interference from large GPL micelles in CASA motility measurements, all samples were washed via centrifugation after treatment at $500 \boldsymbol{g}$ for 3 min, resuspended in RT BWW and immediately analysed for motility with no further incubation. Additionally, 4-HNE cellular adduction ('Flow-cytometric measurement of cellular 4-hydroxynonenal adduction' section) and 


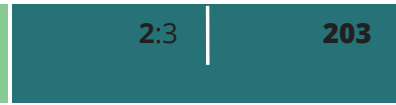

free 4-HNE in the spent medium ('Measurement of 4-hydroxynonenal within the spent media' section) were measured following GPL supplementation in the presence of an oxidative challenge using $50 \mu \mathrm{M} \mathrm{AA}$.

\section{Experiment 2: Addition of ultrasonicated glycerophospholipids to stallion sperm storage media to aid in resistance to oxidative stress}

To ascertain whether exogenous GPL in sperm storage media can improve the quality of spermatozoa $(n=9$ ejaculates), stallion spermatozoa were resuspended in BWW with and without the addition of GPL $(0.1 \% \mathrm{v} / \mathrm{v})$ and incubated at $17^{\circ} \mathrm{C}$ for $72 \mathrm{~h}$. Motility ('Evaluation of sperm motility' section) and viability (SYTOX ${ }^{\mathrm{mm}}$ green; 'Flow cytometric measurement of mitochondrial ROS' section) were analysed every $24 \mathrm{~h}$ (24, 48 and $72 \mathrm{~h}$ ). To avoid interference from large GPL micelles in CASA motility measurements, all samples were centrifuged after treatment at $500 \boldsymbol{g}$ for $3 \mathrm{~min}$, resuspended in RT BWW and immediately analysed for motility with no further incubation.

\section{Results}

Experiment 1: Incubation of stallion spermatozoa with glycerophospholipids in the presence of induced oxidative stress

When GPL were available to stallion spermatozoa during an AA-induced oxidative challenge, supplemented spermatozoa had higher total motility at 25, 50 and $100 \mu \mathrm{M}$ AA doses $(44.2 \pm 7.2$ vs $66.7 \pm 3.8 \%, 14.4 \pm 4.1$ vs $64.4 \pm 8.7 \%$ and $2 \pm 1$ vs $68.8 \pm 2.9 \%$, respectively; all $P \leq 0.001$; Fig. 1A). The GPL-supplemented spermatozoa also displayed improved progressive motility at 25,50 and $100 \mu \mathrm{M}$ AA doses $(9.9 \pm 1.7$ vs $27.7 \pm 2.6 \%, 1.4 \pm 0.6$ vs $28.4 \pm 2.8 \%$ and $0 \pm 0$ vs $9.3 \pm 2.6 \%$, respectively; all $P \leq 0.001$; Fig. $1 \mathrm{~B}$ ). It was also noted that GPL-supplemented spermatozoa were able to maintain the same level of total motility across all AA doses (Fig. 1A; overall mean of $67.7 \pm 1.5 \% ; P>0.05$ ).

Additional sperm motility parameters were analysed throughout the oxidative challenge, demonstrating that when GPL were available to stallion spermatozoa, straight line velocity (VSL; $40.4 \pm 5.3$ vs $70.6 \pm 4.9 \mu \mathrm{m} / \mathrm{s}, 21.6 \pm 3.8$ vs $69.2 \pm 5.8 \mu \mathrm{m} / \mathrm{s}$ and $9.5 \pm 2.1 \mathrm{vs} 50.9 \pm 4.1 \mu \mathrm{m} / \mathrm{s}$ ) curvilinear velocity (VCL; $143.4 \pm 13$ vs $204.6 \pm 3.6 \mu \mathrm{m} / \mathrm{s}, 82.1 \pm 7.5$ vs $193 \pm 6.6 \mu \mathrm{m} / \mathrm{s}$ and $40.8 \pm 10 \mathrm{vs} 160.7 \pm 7.8 \mu \mathrm{m} / \mathrm{s})$ and average path velocity (VAP; $69.5 \pm 10$ vs $113.9 \pm 3.7 \mu \mathrm{m} / \mathrm{s}, 31.3 \pm 5.2$ vs $104.3 \pm 5.1 \mu \mathrm{m} / \mathrm{s}$ and $13.4 \pm 2.9$ vs $81.9 \pm 5.9 \mu \mathrm{m} / \mathrm{s}$ ) all improved $(P \leq 0.001)$ compared to the non-supplemented spermatozoa at 25, 50 and $100 \mu \mathrm{M}$ AA doses, respectively.
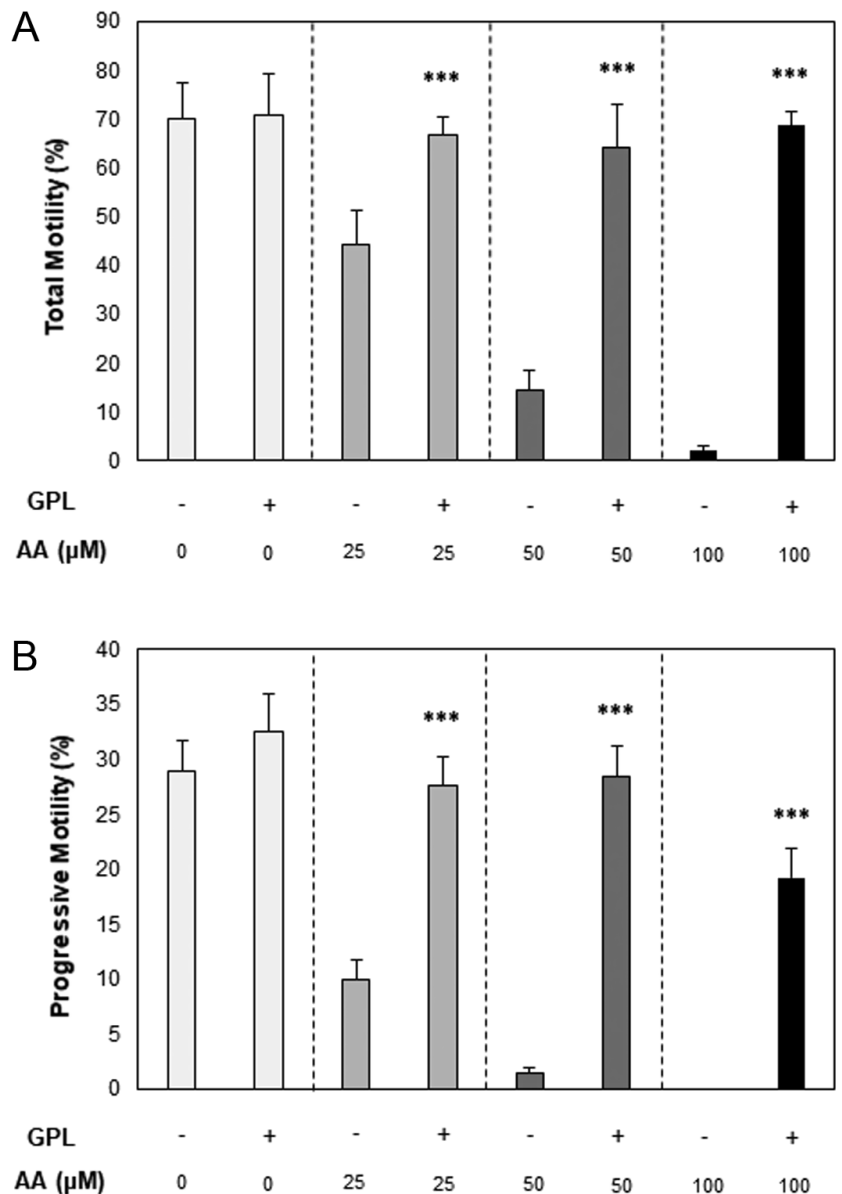

Figure 1 Dose-response curves of total and progressive motility of stallion spermatozoa vs arachidonic acid (AA) concentration. (A) Total motility and (B) progressive motility of stallion spermatozoa, obtained after incubation in the presence of increasing concentrations of arachidonic acid only (AA; -) or in the presence of increasing concentrations of arachidonic acid with the addition of GPL (+). All data are displayed as means \pm S.E.M. ( ${ }^{* *} P \leq 0.001$; Student's $t$-test was used for 0, 25 and $50 \mu \mathrm{M} A A$ data; Wilcoxon signed rank test was used for $100 \mu \mathrm{M}$ AA data).

To determine whether the improved motility in the presence of GPL (Fig. 1) was due to MLR and ROS amelioration, a flow cytometric MSR assay was conducted. When GPL were present in the incubation media, mitochondrial ROS levels were reduced at 25, 50 and 100 $\mu \mathrm{M}$ AA doses $(86 \pm 4$ vs $33.2 \pm 8 \%, 9.7 \pm 3.8$ vs $43.8 \pm 11.1 \%$ and $98.2 \pm 0.6$ vs $74.8 \pm 6.11 \%$, respectively; $P \leq 0.001$; Fig. 2A). Furthermore, spermatozoa supplemented with GPL showed no loss of viability at all AA concentrations assessed (overall mean of $82.2 \pm 0.7 \%$, $P>0.05)$ whereas the non-supplemented spermatozoa showed a reduction in viability at 25,50 and $100 \mu \mathrm{M}$ AA doses $(71.9 \pm 3.4$ vs $83.2 \pm 1.7 \%, P \leq 0.01 ; 44.9 \pm 4.3$ vs $82.4 \pm 3 \%, P \leq 0.001$; and $13.5 \pm 2.9$ vs $80.2 \pm 1.6 \%$, $P \leq 0.001$ respectively; Fig. 2B). 
To analyse the impact of time on lipid peroxidation; stallion spermatozoa were incubated with or without GPL in the presence of $50 \mu \mathrm{M}$ AA only. Cellular 4-HNE adduction, free 4-HNE adducts within the spent media, and viability were measured at 0,2 and $4 \mathrm{~h}$ of incubation at $37^{\circ} \mathrm{C}$. The addition of GPL to the incubation media resulted fewer 4 -HNE positive cells at 2 and $4 \mathrm{~h}(36.1 \pm 3.9 \mathrm{vs}$ $20.9 \pm 3.3 \%, 32.9 \pm 2.7$ vs $20.9 \pm 2.3 \%$, respectively; $P \leq 0.05$; Fig. 3A), and a higher concentration of 4-HNE adducts within the spent media at 0,2 and $4 \mathrm{~h}(0.028 \pm 0.003$ vs $0.04 \pm 0.003 \mu \mathrm{g} / \mathrm{mL}, P \leq 0.05 ; 0.02 \pm 0.004$ vs $0.037 \pm 0.003$ $\mu \mathrm{g} / \mathrm{mL}, P \leq 0.001 ; 0.026 \pm 0.003$ vs $0.039 \pm 0.004 \mu \mathrm{g} / \mathrm{mL}$, $P \leq 0.001$, respectively; Fig. 3B). The addition of GPL to the incubation media also resulted in higher viability at 2 and $4 \mathrm{~h}$ time points compared to the non-supplemented treatment $(38.5 \pm 6.9$ vs $86.4 \pm 2.2 \%, P \leq 0.001$; and $29.1 \pm 8$ vs $71.7 \pm 6.7 \%, P \leq 0.001$, respectively; Fig. $3 \mathrm{C}$ ).

\section{Experiment 2: Addition of glycerophospholipids to stallion sperm storage media to aid in resistance to oxidative stress}

To ascertain whether the addition of GPL to sperm storage media could improve post-storage sperm quality via enhanced resistance to oxidative stress in vitro, stallion spermatozoa were stored over $72 \mathrm{~h}$ with and without GPL at $17^{\circ} \mathrm{C}$. Storage at $17^{\circ} \mathrm{C}$ has previously been found optimal for non-cooled sperm storage by our laboratory, sperm metabolism is not curtailed at this temperature, and therefore, spermatozoa suffer the consequences of mitochondrial ROS production (Gibb et al. 2018). When GPL were added to sperm storage media, an improvement in progressive motility was observed after $24 \mathrm{~h}(19.9 \pm 3.8$ vs $29.3 \pm 5.11 ; P \leq 0.05)$. An improvement in sperm viability was observed after $48 \mathrm{~h}$, as well as an improvement in progressive motility $(69.5 \pm 4.2$ vs $84.2 \pm 2.2 \%, P \leq 0.01$; and $18.2 \pm 2.6$ vs $27.9 \pm 3.8 \%, P \leq 0.01$, respectively; Fig. $4 \mathrm{~B})$. Likewise, after $72 \mathrm{~h}$ of sperm storage there was an improvement in sperm viability and total motility compared to the non-supplemented group $(66.4 \pm 2.6$ vs $78.1 \pm 2.9 \%, P \leq 0.01$; and $53 \pm 5.6$ vs $66.3 \pm 3.5 \%, P \leq 0.05$, respectively; Fig. 4C).

\section{Discussion}

This is the first study to confirm that stallion spermatozoa are capable of replacing oxidized membrane GPL for exogenously supplied GPL to repair cellular membranes, restore sperm functions and protect against oxidative stress in vitro. This study supports previously published findings in which membrane lipid replacement therapy utilizing NTFactor Lipids restored mitochondrial function in vivo; reducing fatigue in aged patients and patients suffering from a variety of fatigue-related clinical diagnoses, such as fibromyalgia, Lyme's disease, and chronic fatigue syndrome (Nicolson \& Ellithorpe 2006, Nicolson 2014, Nicolson \& Ash 2014), while increasing mitochondrial function (Agadjanyan et al. 2003, Nicolson 2014). NTFactor ${ }^{\circ}$ Lipids are a commercially available mixture of the most common glycerophospholipids found within cell membranes; as well as unsaturated fatty acids, and this natural supplement has previously been shown to provide resistance to oxidizing agents such as hydrogen peroxide
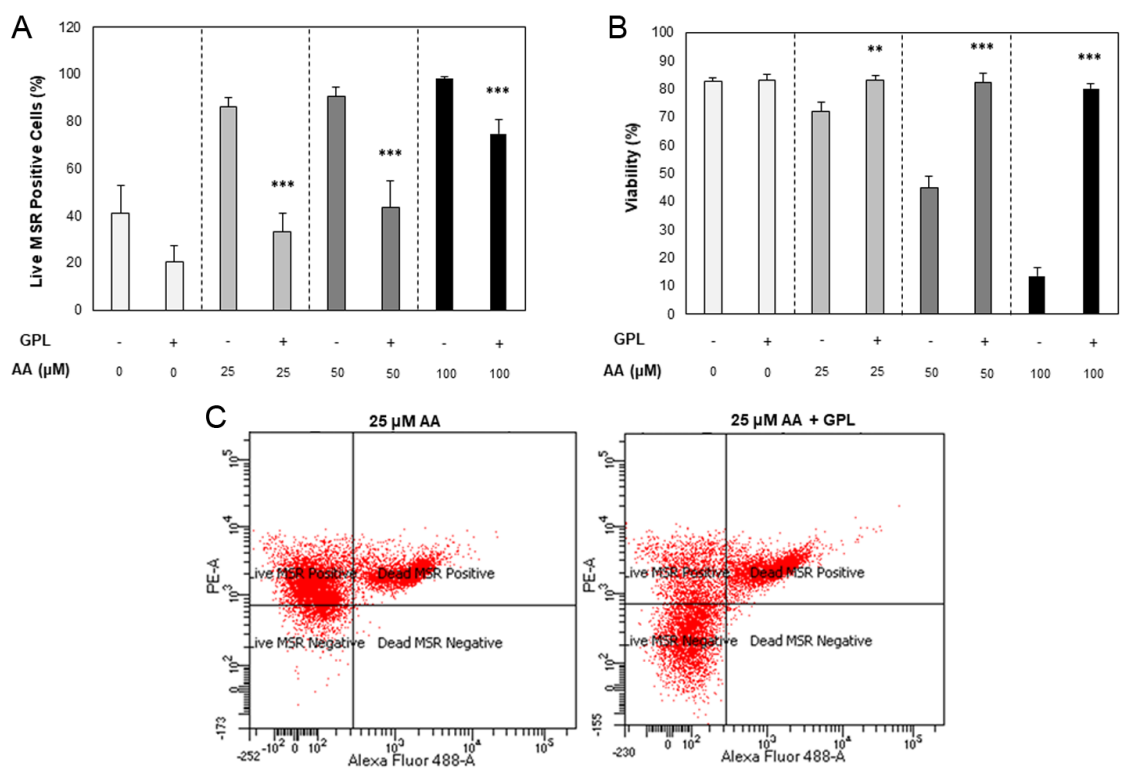

Figure 2 Flow cytometric analysis of mitochondrial ROS within stallion spermatozoa. (A) Mitochondrial ROS levels measured by MitoSOX'M Red reagent (MSR), (B) Total cell viability measured with SYTOX ${ }^{\text {TM }}$ Green Dead Cell Stain obtained after co-incubation in the presence of increasing concentrations of arachidonic acid only (AA; -) or in the presence of increasing concentrations of arachidonic acid with the addition of GPL (+), and (C) a representative flow cytometric dot plot depicting the fluorescent changes in spermatozoa after incubation with $25 \mu \mathrm{M}$ AA (left) and $25 \mu \mathrm{M}$ AA with the addition of $\mathrm{GPL}$ (right). All data are displayed as means \pm S.E.M. $\left({ }^{*} P \leq 0.05, * * P \leq 0.01, * * * P \leq 0.001\right.$; Student's $t$-test). https://raf.bioscientifica.com https://doi.org/10.1530/RAF-21-0028 (c) 2021 The authors Published by Bioscientifica Ltd

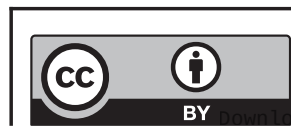

This work is licensed under a Creative Commons Attribution 4.0 International License. 
A
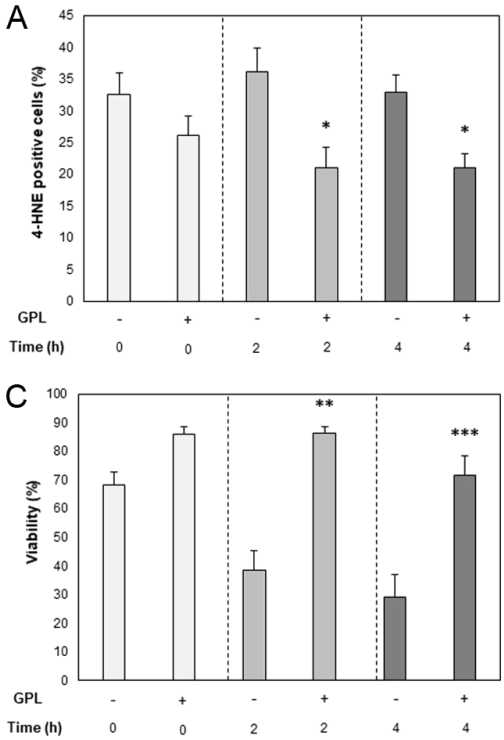
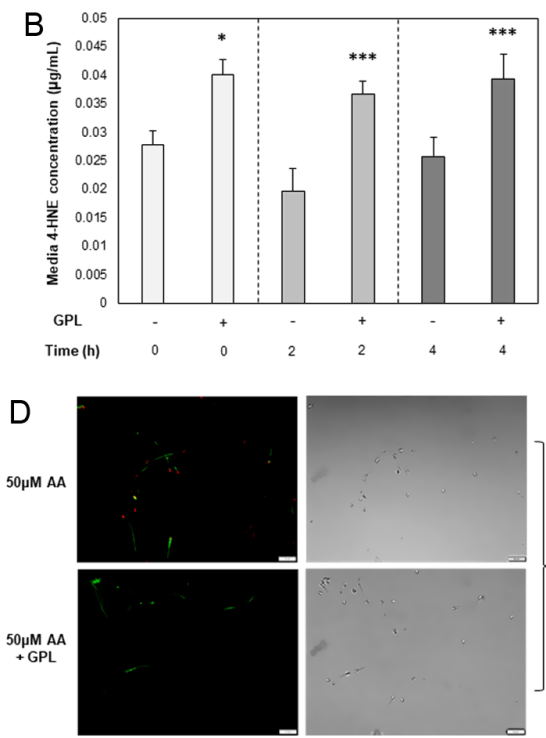

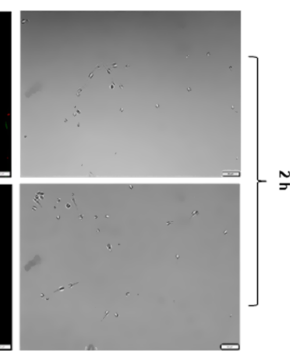

Figure 3 Analysis of 4-HNE adduction. (A) Total cellular 4-HNE adduction, utilizing $\alpha$-HNE primary and Alexa Fluor 488 secondary antibodies, (B) Concentration of 4-HNE adducts within the spent sperm storage media and, (C) Total cell viability measured with LIVE/DEAD ${ }^{\text {TM }}$ fixable far red dead cell stain obtained after co-incubation in the presence of $50 \mu \mathrm{M}$ arachidonic acid only (AA; -) or in the presence of $50 \mu \mathrm{M} \mathrm{AA}$ with the addition of GPL (+), measured at regular $2 \mathrm{~h}$ intervals over a total of $4 \mathrm{~h}$. (D) Fluorescent and phase images of spermatozoa depicting 4-HNE adduction (green) utilizing $\alpha$-HNE primary and Alexa Fluor 488 secondary antibodies, after $2 \mathrm{~h}$ incubation with 25 $\mu \mathrm{M}$ AA only (top) and $25 \mu \mathrm{M}$ AA with the addition of GPL (Bottom). Red fluorescence (PI) indicates a dead cell. Original magnification $\times 400$. All data are displayed as means \pm S.E.M. $\left({ }^{*} P \leq 0.05, * \star P \leq 0.01\right.$, $\star \star \star P \leq 0.001$; Student's $t$-test).
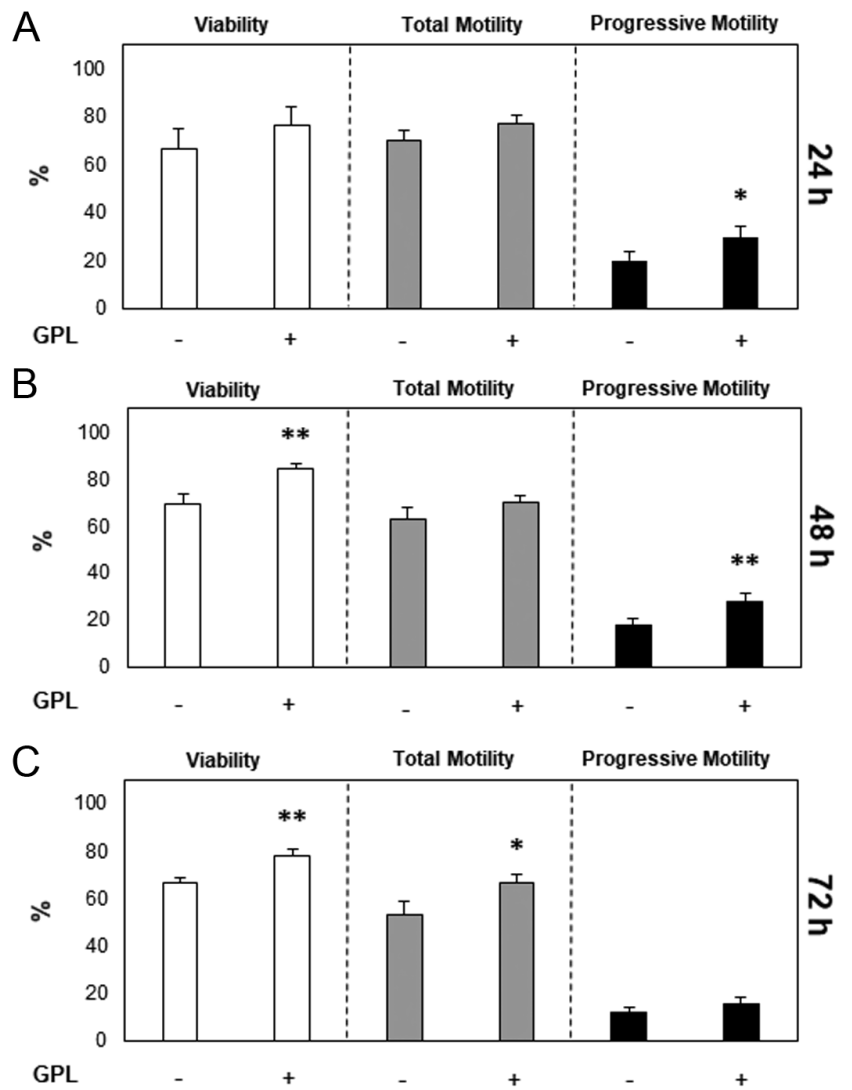

Figure 4 Sperm were stored at $17^{\circ} \mathrm{C}$ with the addition of GPL. Sperm were stored at $17^{\circ} \mathrm{C}$ in BWW only (-) or BWW with the addition of GPL (+). Total cell viability measured with SYTOX ${ }^{\mathrm{TM}}$ Green Dead Cell Stain and sperm motility parameters were measured at (A) $24 \mathrm{~h}$, (B) $48 \mathrm{~h}$, and (C) $72 \mathrm{~h}$. All data are displayed as means \pm S.E.M. ( ${ }^{*} P \leq 0.05 .{ }^{*} P \leq 0.01 ;$ REML analysis). Published by Bioscientifica Ltd
$\left(\mathrm{H}_{2} \mathrm{O}_{2}\right)$, improving viability and motility of human spermatozoa in vitro (Ferreira et al. 2018).

Oxidative damage in stallion spermatozoa was stimulated via co-incubation with varying doses of AA (Hong et al. 1986), promoting degradation of cell membranes by producing toxic lipid aldehydes, causing cell damage and dysregulating cellular functions (Aitken et al. 2012b). At this point, we sought to clarify that AA was not one of the PUFA contained in NTFactor ${ }^{\circ}$ Lipids (Nicolson \& Ash 2017), the commercial preparation of the GPL utilized in this study and would not confound the results. Published compositions of NTFactor ${ }^{\circ}$ Lipids did not reveal the presence of AA (Nicolson 2016). A previous study by Ferreira et al. (2018) utilized $\mathrm{H}_{2} \mathrm{O}_{2}$ to induce oxidative stress in human spermatozoa. In this situation, supplementation with fluorescently labelled GPL allowed visualization of incorporated lipids to ensure that lipid membrane exchange had occurred. As $\mathrm{H}_{2} \mathrm{O}_{2}$ can be directly scavenged by GPL, for this study, we selected AA as an alternative oxidative stressor, as we wished to ensure that the effects we were observing were not due to the direct sequestering of $\mathrm{H}_{2} \mathrm{O}_{2}$ by GPL, as opposed to the effects of MLR.

Flow cytometric analysis confirmed that 4-HNE adduction was significantly diminished when GPL micelles were made available to oxidatively stressed spermatozoa (Fig. 3A). Additionally, the significant reduction of mitochondrial ROS production observed in this study (Fig. 2A) could be attributed to the reduction in the downstream effects of 4-HNE adduction; 4-HNE exacerbates mitochondrial superoxide production by preferential adduction to SDHA, perturbing mitochondrial 
function and driving ROS production (Ball et al. 2001, Aitken et al. 2012b). This increase in ROS can further peroxidise additional membrane lipids, increasing the production of 4-HNE, and as a consequence, this can further exacerbate the stress cycle (Aitken et al. 2012b). The ability of spermatozoa to substitute oxidized GPL from their plasma and mitochondrial membranes with fresh GPL from the extracellular milieu has previously been demonstrated (Ferreira et al. 2018).

When peroxidation of membrane phospholipid PUFAs occurs, active removal or repair processes are initiated. One such process involves the cleavage of the damaged PUFA at the site of peroxidation by phospholipase A2 $\left(\mathrm{PLA}_{2}\right)$ enzymes, which play an intrinsic role in protecting cell membranes from oxidative damage (Sevanian \& Kim 1985). This process has been shown to be present and active in spermatozoa (Collodel et al. 2020). Indeed, $\mathrm{PLA}_{2}$ activity is highly correlated with the degree of lipid peroxidation in membranes (Sevanian et al. 1983), and if not replaced by lipids from exogenous sources, $\mathrm{PLA}_{2}$ activity may be sufficient to perturb cellular membranes to the point of cell lysis via the creation of lysophosphlipids (Shier 1979). Exogenously supplied GPL, such as those used in the present study, may be transported across membranes by binding to transmembrane phospholipid-translocase proteins (ATPindependent biogenic flippases), which have recently been characterized in the outer intracellular membranes of bovine spermatozoa (Rajasekharan et al. 2013). GPL may also be taken up by most cells as small liposomes and lipid globules that enter the cell by endocytosis (Nicolson 2014, Nicolson \& Ash 2017). Organelles such as mitochondria are able to transfer damaged membrane lipids via direct contact, as well as via lipid transport proteins that shuttle membrane phospholipids between inner and outer membranes (Chatterjee \& Gagnon 2001). Once they arrive at the site of a damaged membrane, GPL can then be then enzymatically modified to replace damaged lipids (Nicolson \& Ash 2017). The lower levels of 4-HNE cellular adduction (Fig. 4A) and increased 4-HNE concentration within the spent media (Fig. 4B) observed following GPL supplementation lends support to the hypothesis that this membrane lipid replacement mechanism is indeed functional in stallion spermatozoa, as GPL supplementation inhibited the downstream effects of lipid peroxidation before reactive aldehydes such as 4-HNE were produced and the subsequent mitochondrial ROS increase was able to decrease cell viability (Figs 3A and 4C; Aitken et al. 1989). Therefore, membrane lipid replacement must be occurring whilst still in the lipid hydroperoxide intermediate metabolite stage (such as 15-HPETE, which is then later degraded into 4-HNE within the media), but before being completely degraded to 4 -HNE cellular adducts and propagating the oxidative stress cycle (Aitken et al. 2012b, Ayala et al. 2014).

The underlying mechanism by which membrane lipid replacement functions in vitro to modify spermatozoa are yet to be conclusively elucidated; at the time of this study, there was only one publication on the use of MLR to treat spermatozoa in vitro (Ferreira et al. 2018). The plasma membrane surrounding the sperm head displays differences in lipid compositions and therefore, differences in fluidities (Oresti et al. 2011). Membranes with these structural asymmetries have been shown to be in contact with intracellular membranes allowing the exchange of lipids through direct membrane-membrane contact (Wolfe et al. 1998). Whether this lipid exchanging mechanism is entirely passive or involves more complex components such as lipid transport proteins or fatty acid cleaving enzymes such as $\mathrm{PLA}_{2}$ is unclear and warrants further investigation.

The addition of GPL micelles to AA-treated spermatozoa significantly improved viability (Figs 2B and $3 \mathrm{C}$ ), as well as a number of motility parameters (Fig. 1). This is most certainly a downstream effect of the amelioration of the aforementioned lipid peroxidation and oxidative stress cycle, as 4-HNE adduction to succinate dehydrogenase (complex II of the mitochondrial electron transport chain) perturbs ATP production and instigates the apoptotic cascade (Koppers et al. 2011). When this pathway is activated, mitochondrial ROS rapidly triggers a loss of transmembrane potential, followed by a loss of ATP production necessary for motility, caspase activation and membrane disorganization (phosphatidylserine translocation). This is followed by oxidative DNA damage and strand breakage, and ultimately cell death (Aitken et al. $2012 b$ ).

The observation of the protective effects of GPL during an oxidative stress challenge led to the notion that exogenous GPL micelles might be a beneficial additive to sperm storage media, ameliorating ROS and therefore improving the post-storage quality of stallion spermatozoa stored at $17^{\circ} \mathrm{C}$. During conventional sperm storage (chilled and cryopreserved) the majority of damage to spermatozoa during occurs at the sperm plasma membrane when it transitions between a fluid (liquid crystalline) phase to a gel state during cooling and rewarming, resulting in irreversible mechanical damage (Sieme et al. 2015), which may not necessarily be oxidative in nature. This damage affects the functional and molecular state of the sperm

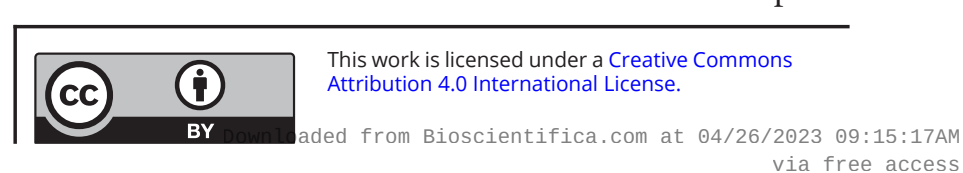


membrane, resulting in a reduction of membrane fluidity (Aitken et al. 2006). Cooling-induced reduction in sperm motility and function has formerly been suspected to be a symptom of the formation of ROS and successive lipid peroxidation (Aitken 1995, Chatterjee \& Gagnon 2001). However, the irreversible mechanical damage which the plasma membrane endures during this process may far outweigh the damage sustained from the formation of ROS. Previous studies have also established that unlike other species, such as humans (Surmon et al. 2009), antioxidant supplementation during cooled storage is of minimal benefit to stallion spermatozoa (Baumber et al. 2000, 2005). Therefore, this study focused on $17^{\circ} \mathrm{C}$ sperm storage, a temperature which this group has previously shown to be optimal for long-term storage of stallion spermatozoa (Gibb et al. 2018), but one at which lipid peroxidation is a recognized consequence of uninhibited sperm metabolism (Aitken et al. 2012a). Supplementation of stallion spermatozoa with GPL during $17^{\circ} \mathrm{C}$ in vitro storage successfully diminished the effects of lipid peroxidation, most certainly due to reasons stated previously, improving sperm viability and motility parameters post 24,48 and $72 \mathrm{~h}$ storage (Fig. 4).

The authors acknowledge the limitations of the study, being that a conclusive mechanism was not established by the use of inhibitors, in the case of $\mathrm{PLA}_{2}$. These further experiments aim to be the main focus of future studies.

In conclusion, our results indicate that incubation of stallion spermatozoa with a mixture of sub- $\mu$ m-sized GPL micelles at a concentration of $0.1 \%$ (Nicolson 2010), does indeed result in the incorporation of exogenous GPL into the sperm plasma and inner membranes as previously described in human spermatozoa by Ferreira et al. (2018). Due to this lipid substitution, incubation of stallion spermatozoa with GPL micelles successfully diminished lipid peroxidation, improving the viability and motility parameters of stallion spermatozoa during in vitro storage at $17^{\circ} \mathrm{C}$. With this knowledge, the investigators first propose that glycerophospholipids may be a beneficial additive within commercial semen extender preparations for stallions and possibly other mammalian spermatozoa as well, and secondly, further exploration should be considered into possible benefits of utilizing GPL as an in vivo oral supplement for animals who exhibit poor fertility as a result of elevated sperm lipid peroxidation and oxidative DNA damage.

\section{Declaration of interest}

The authors declare that there is no conflict of interest that could be perceived as prejudicing the impartiality of the research reported.

\section{Funding}

This work was supported by Australian Research Council Linkage grant \#LP160100824.

\section{Author contribution statement}

A $M$ conducted the experiments, statistical analysis and wrote the manuscript. R A provided guidance and assisted with manuscript editing. G N supplied NTFactor ${ }^{\circledR}$ Lipids and assisted with manuscript editing. A R S aided with experiments and stallion semen collections. A $S$ and $\mathrm{G} D$ provided guidance. $Z \mathrm{G}$ conceived and funded the study, assisted with stallion semen collections, and reviewed and edited the manuscript.

\section{Acknowledgements}

The authors thank the University of Newcastle's Analytical and Biomolecular Research Facility for providing flow cytometry, and Dr Gonzalo Ferreira et al. (Ferreira et al. 2018) for previous work optimizing NTFactor ${ }^{\circledR}$ Lipids for the treatment of human spermatozoa, which were an integral component of this study.

\section{References}

Agadjanyan M, Vasilevko V, Ghochikyan A, Berns P, Kesslak P, Settineri RA, \& Nicolson GL 2003 Nutritional supplement (NT Factor $^{\text {T"I })}$ restores mitochondrial function and reduces moderately severe fatigue in aged subjects. Journal of Chronic Fatigue Syndrome $\mathbf{1 1}$ 23-36. (https://doi.org/10.1300/J092v11n03_03)

Aitken RJ 1995 Free radicals, lipid peroxidation and sperm function. Reproduction, Fertility, and Development 7 659-668. (https://doi. org/10.1071/rd9950659)

Aitken RJ, Clarkson JS \& Fishel S 1989 Generation of reactive oxygen species, lipid peroxidation, and human sperm function. Biology of Reproduction 41 183-197. (https://doi.org/10.1095/biolreprod41.1.183)

Aitken RJ, Wingate JK, De Iuliis GN, Koppers AJ \& Mclaughlin EA 2006 Cis-unsaturated fatty acids stimulate reactive oxygen species generation and lipid peroxidation in human spermatozoa. Journal of Clinical Endocrinology and Metabolism 91 4154-4163. (https://doi. org/10.1210/jc.2006-1309)

Aitken RJ, Gibb Z, Mitchell LA, Lambourne SR, Connaughton HS \& De Iuliis GN 2012a Sperm motility is lost in vitro as a consequence of mitochondrial free radical production and the generation of electrophilic aldehydes but can be significantly rescued by the presence of nucleophilic thiols. Biology of Reproduction 87 110. (https:// doi.org/10.1095/biolreprod.112.102020)

Aitken RJ, Whiting S, De Iuliis GN, Mcclymont S, Mitchell LA \& Baker MA 2012b Electrophilic aldehydes generated by sperm metabolism activate mitochondrial reactive oxygen species generation and apoptosis by targeting succinate dehydrogenase. Journal of Biological Chemistry 287 33048-33060. (https://doi.org/10.1074/jbc. M112.366690)

Aurich C 2005 Factors affecting the plasma membrane function of cooled-stored stallion spermatozoa. Animal Reproduction Science 89 65-75. (https://doi.org/10.1016/j.anireprosci.2005.06.025)

Ayala A, Munoz MF \& Arguelles S 2014 Lipid peroxidation: production, metabolism, and signaling mechanisms of malondialdehyde and 4-hydroxy-2-nonenal. Oxidative Medicine and Cellular Longevity 2014 360438. (https://doi.org/10.1155/2014/360438)

Baker MA, Weinberg A, Hetherington L, Villaverde AI, Velkov T, Baell J \& Gordon CP 2015 Defining the mechanisms by which the

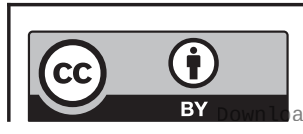

This work is licensed under a Creative Commons Attribution 4.0 International License. 
reactive oxygen species by-product, 4-hydroxynonenal, affects human sperm cell function. Biology of Reproduction 92 108. (https://doi. org/10.1095/biolreprod.114.126680)

Ball BA, Vo AT \& Baumber J 2001 Generation of reactive oxygen species by equine spermatozoa. American Journal of Veterinary Research $\mathbf{6 2}$ 508-515. (https://doi.org/10.2460/ajvr.2001.62.508)

Batellier F, Vidament M, Fauquant J, Duchamp G, Arnaud G, Yvon JM \& Magistrini M 2001 Advances in cooled semen technology. Animal Reproduction Science 68 181-190. (https://doi. org/10.1016/s0378-4320(01)00155-5)

Baumber J, Ball BA, Gravance CG, Medina V \& Davies-Morel MC 2000 The effect of reactive oxygen species on equine sperm motility, viability, acrosomal integrity, mitochondrial membrane potential, and membrane lipid peroxidation. Journal of Andrology 21 895-902. (https://doi.org/10.1002/j.1939-4640.2000.tb03420.x)

Baumber J, Ball BA \& Linfor JJ 2005 Assessment of the cryopreservation of equine spermatozoa in the presence of enzyme scavengers and antioxidants. American Journal of Veterinary Research 66 772-779. (https://doi.org/10.2460/ajvr.2005.66.772)

Biggers J, Whitten W, Whittingham D \& Daniel J 1971 Methods in Mammalian Embryology, pp. 86-116. San Francisco, CA: Freeman.

Brinsko SP, Crockett EC \& Squires EL 2000a Effect of centrifugation and partial removal of seminal plasma on equine spermatozoal motility after cooling and storage. Theriogenology $\mathbf{5 4} 129-136$. (https:// doi.org/10.1016/S0093-691X(00)00331-9)

Brinsko SP, Van Wagner GS, Graham JK \& Squires EL $2000 b$ Motility, morphology and triple stain analysis of fresh, cooled and frozen-thawed stallion spermatozoa. Journal of Reproduction and Fertility Supplement 56 111-120.

Bromfield EG, Aitken RJ, Mclaughlin EA \& Nixon B 2017 Proteolytic degradation of heat shock protein A2 occurs in response to oxidative stress in male germ cells of the mouse. Molecular Human Reproduction 23 91-105. (https://doi.org/10.1093/molehr/gaw074)

Chatterjee S \& Gagnon C 2001 Production of reactive oxygen species by spermatozoa undergoing cooling, freezing, and thawing. Molecular Reproduction and Development 59 451-458. (https://doi.org/10.1002/ mrd.1052).

Collodel G, Castellini C, Iacoponi F, Noto D \& Signorini C 2020 Cytosolic phospholipase $\mathrm{A}(2)$ and $\mathrm{F}(2)$ isoprostanes are involved in semen quality and human infertility: a study on leucocytospermia, varicocele and idiopathic infertility. Andrologia 52 e13465. (https:// doi.org/10.1111/and.13465)

Fahy E, Subramaniam S, Brown HA, Glass CK, Merrill AH, Murphy RC, Raetz CR, Russell DW, Seyama Y, Shaw W, et al. 2005 A comprehensive classification system for lipids. Journal of Lipid Research 46 839-861. (https://doi.org/10.1194/jlr.E400004-JLR200).

Ferreira G, Costa C, Bassaizteguy V, Santos M, Cardozo R, Montes J, Settineri R \& Nicolson GL 2018 Incubation of human sperm with micelles made from glycerophospholipid mixtures increases sperm motility and resistance to oxidative stress. PLOS ONE 13 e0197897. (https://doi.org/10.1371/journal.pone.0197897)

Flesch FM \& Gadella BM 2000 Dynamics of the mammalian sperm plasma membrane in the process of fertilization. Biochimica et Biophysica Acta 1469 197-235. (https://doi.org/10.1016/s0304-4157(00)00018-6)

Gaschler MM \& Stockwell BR 2017 Lipid peroxidation in cell death. Biochemical and Biophysical Research Communications 482 419-425. (https://doi.org/10.1016/j.bbrc.2016.10.086)

Gibb Z, Clulow JR, Aitken RJ \& Swegen A 2018 First publication to describe a protocol for the liquid storage of stallion spermatozoa for 7 days. Journal of Equine Veterinary Science 66 37-40. (https://doi. org/10.1016/j.jevs.2018.05.016)

Hong CY, Shieh CC, Wu P, Huang JJ \& Chiang BN 1986 Effect of phosphatidylcholine, lysophosphatidylcholine, arachidonic acid and docosahexaenoic acid on the motility of human sperm. International Journal of Andrology 9 118-122. (https://doi. org/10.1111/j.1365-2605.1986.tb00874.x)
Koppers AJ, Mitchell LA, Wang P, Lin M \& Aitken RJ 2011 Phosphoinositide 3-kinase signalling pathway involvement in a truncated apoptotic cascade associated with motility loss and oxidative DNA damage in human spermatozoa. Biochemical Journal 436 687-698. (https://doi.org/10.1042/BJ20110114)

Lenzi A, Picardo M, Gandini L \& Dondero F 1996 Lipids of the sperm plasma membrane: from polyunsaturated fatty acids considered as markers of sperm function to possible scavenger therapy. Human Reproduction Update 2 246-256. (https://doi.org/10.1093/ humupd/2.3.246)

Moazamian R, Polhemus A, Connaughton H, Fraser B, Whiting S, Gharagozloo P \& Aitken RJ 2015 Oxidative stress and human spermatozoa: diagnostic and functional significance of aldehydes generated as a result of lipid peroxidation. Molecular Human Reproduction 21 502-515. (https://doi.org/10.1093/molehr/ gav014)

Nicolson GL 2005 Lipid replacement/antioxidant therapy as an adjunct supplement to reduce the adverse effects of cancer therapy and restore mitochondrial function. Pathology Oncology Research 11 139-144. (https://doi.org/10.1007/BF02893390)

Nicolson GL 2007 Metabolic syndrome and mitochondrial function: molecular replacement and antioxidant supplements to prevent membrane peroxidation and restore mitochondrial function. Journal of Cellular Biochemistry 100 1352-1369 . (https://doi.org/10.1002/ jcb.21247).

Nicolson GL 2010 Lipid replacement therapy: a nutraceutical approach for reducing cancer-associated fatigue and the adverse effects of cancer therapy while restoring mitochondrial function. Cancer Metastasis Reviews 29 543-552 . (https://doi.org/10.1007/s10555-010-9245-0).

Nicolson GL 2014 Mitochondrial dysfunction and chronic disease: treatment with natural supplements. Integrative Medicine 13 35-43.

Nicolson GL 2016 Membrane lipid replacement: clinical studies using a natural medicine approach to restoring membrane function and improving health. International Journal of Clinical Medicine 7 133-143. (https://doi.org/10.4236/ijcm.2016.72015).

Nicolson GL \& Ash ME 2014 Lipid replacement therapy: a natural medicine approach to replacing damaged lipids in cellular membranes and organelles and restoring function. Biochimica et Biophysica Acta 1838 1657-1679. (https://doi.org/10.1016/j.bbamem.2013.11.010)

Nicolson GL \& Ash ME 2017 Membrane lipid replacement for chronic illnesses, aging and cancer using oral glycerolphospholipid formulations with fructooligosaccharides to restore phospholipid function in cellular membranes, organelles, cells and tissues. Biochimica et Biophysica Acta: Biomembranes 1859 1704-1724. (https:// doi.org/10.1016/j.bbamem.2017.04.013)

Nicolson GL \& Conklin KA 2008 Reversing mitochondrial dysfunction, fatigue and the adverse effects of chemotherapy of metastatic disease by molecular replacement therapy. Clinical and Experimental Metastasis 25 161-169. (https://doi.org/10.1007/s10585-007-9129-z)

Nicolson GL \& Ellithorpe R 2006 Lipid replacement and antioxidant nutritional therapy for restoring mitochondrial function and reducing fatigue in chronic fatigue syndrome and other fatiguing illnesses. Journal of Chronic Fatigue Syndrome 13 57-68. (https://doi.org/10.1300/ J092v13n01_06)

Oresti GM, Luquez JM, Furland NE \& Aveldaño MI 2011 Uneven distribution of ceramides, sphingomyelins and glycerophospholipids between heads and tails of rat spermatozoa. Lipids 46 1081-1090. (https://doi.org/10.1007/s11745-011-3601-x)

Ortega Ferrusola C, Gonzalez Fernandez L, Salazar Sandoval C, Macias Garcia B, Rodriguez Martinez H, Tapia JA \& Pena FJ 2010 Inhibition of the mitochondrial permeability transition pore reduces "apoptosis like" changes during cryopreservation of stallion spermatozoa. Theriogenology 74 458-465. (https://doi.org/10.1016/j. theriogenology.2010.02.029)

Rajasekharan A, Francis VG \& Gummadi SN 2013 Biochemical evidence for energy-independent flippase activity in bovine

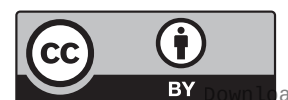


epididymal sperm membranes: an insight into membrane biogenesis. Reproduction 146 209-220. (https://doi.org/10.1530/REP-13-0121)

Saalu LC 2010 The incriminating role of reactive oxygen species in idiopathic male infertility: an evidence based evaluation. Pakistan Journal of Biological Sciences 13 413-422. (https://doi.org/10.3923/pjbs.2010.413.422)

Saleh RA \& Agarwal A 2002 Oxidative stress and male infertility: from research bench to clinical practice. Journal of Andrology 23 737-752. (https://doi.org/10.1002/j.1939-4640.2002.tb02324.x)

Sevanian A \& Kim E 1985 Phospholipase A2 dependent release of fatty acids from peroxidized membranes. Journal of Free Radicals in Biology and Medicine 1 263-271. (https://doi.org/10.1016/0748-5514(85)90130-8)

Sevanian A, Muakkassah-Kelly SF \& Montestruque S 1983 The influence of phospholipase A2 and glutathione peroxidase on the elimination of membrane lipid peroxides. Archives of Biochemistry and Biophysics 223 441-452. (https://doi.org/10.1016/00039861(83)90608-2)

Shier WT 1979 Activation of high levels of endogenous phospholipase A2 in cultured cells. PNAS 76 195-199. (https://doi.org/10.1073/pnas.76.1.195)

Sieme H, Oldenhof H \& Wolkers WF 2015 Sperm membrane behaviour during cooling and cryopreservation. Reproduction in Domestic Animals 50 (Supplement 3) 20-26. (https://doi.org/10.1111/rda.12594)

Spickett CM 2013 The lipid peroxidation product 4-hydroxy-2-nonenal: advances in chemistry and analysis. Redox Biology 1 145-152. (https:// doi.org/10.1016/j.redox.2013.01.007)
Surmon LK, Fleming SD, Aitken RJ, De Iuliis GN, Zieschang JA \& Clark AM 2009 Cryopreservation-induced human sperm DNA damage is predominantly mediated by oxidative stress rather than apoptosis. Human Reproduction 24 2061-2070. (https://doi. org/10.1093/humrep/dep214)

Tallima H \& El Ridi R 2018 Arachidonic acid: physiological roles and potential health benefits: a review. Journal of Advanced Research $\mathbf{1 1}$ 33-41. (https://doi.org/10.1016/j.jare.2017.11.004)

Uribe P, Treulen F, Boguen R, Sánchez R \& Villegas JV 2017 Nitrosative stress by peroxynitrite impairs ATP production in human spermatozoa. Andrologia 49. (https://doi.org/10.1111/and.12615)

Wolfe CA, James PS, Mackie AR, Ladha S \& Jones R 1998 Regionalized lipid diffusion in the plasma membrane of mammalian spermatozoa. Biology of Reproduction 59 1506-1514. (https://doi. org/10.1095/biolreprod59.6.1506)

Zorov DB, Juhaszova M \& Sollott SJ 2014 Mitochondrial reactive oxygen species (ROS) and ROS-induced ROS release. Physiological Reviews 94 909-950. (https://doi.org/10.1152/physrev.00026.2013)

Received in final form 29 June 2021

Accepted 21 July 2021

Accepted Manuscript published online 21 July 2021 (c) 2021 The authors Published by Bioscientifica Ltd

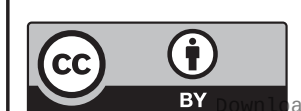

This work is licensed under a Creative Commons Attribution 4.0 International License. 